\title{
Peripheral Facial Palsy in the Setting of Melkersson-Rosenthal Syndrome - Case Report
}

\author{
Paralisia Facial Periférica no Contexto de Sindrome de Melkersson-Rosenthal-Relato de Caso
}

Sabrina Pimentel', Amélia Mendes', Maria José Rosas ${ }^{3}$

\begin{abstract}
Melkersson-Rosenthal syndrome is characterized by recurrent peripheral facial palsy, recurrent or persistent orofacial edema and a fissured tongue. However, this clinical triad occurs only in a minority of cases; mono or oligosymptomatic forms are much more common. The authors describe a case report of a 39-year-old woman with MelkerssonRosenthal syndrome, discuss the evolution of the disease and treatment, highlighting the need of a high clinical suspicion index and a regular follow-up to reduce progression of deficits.
\end{abstract}

Keywords. Peripheral Facial Palsy, Melkersson-Rosenthal Syndrome, Blepharospasm.

Citation. Pimentel S, Mendes A, Rosas MJ. Peripheral Facial Palsy in the Setting of Melkersson-Rosenthal Syndrome - Case Report.
Study performed at Hospital de Sáo João, Porto, Portugal.

1. Resident of Physical and Rehabilitation Medicine; Department of Physical and Rehabilitation Medicine, Hospital de São João, Porto, Portugal.

2. Resident of Neurology; Department of Neurology, Hospital de São João, Porto, Portugal.

3. Senior Doctor of Neurology; Department of Neurology, Hospital de São João, Porto, Portugal.

\section{RESUMO}

A síndrome de Melkersson-Rosenthal é caraterizada por episódios de paralisia facial recorrente, edema orofacial persistente ou recorrente e língua fissurada. Todavia, esta tríade clínica apenas está presente numa minoria de casos; formas mono ou oligossintomáticas são muito mais comuns. As autoras descrevem um caso clínico de uma mulher de 39 anos com síndrome de Melkersson-Rosenthal, discutem a evoluçáo da doença e tratamento, colocando em destaque a necessidade de elevada suspeita clínica e de um acompanhamento regular para reduzir a progressão dos défices.

Unitermos. Paralisia Facial Periférica, Síndrome de Melkersson-Rosenthal, Blefarospasmo.

Citação. Pimentel S, Mendes A, Rosas MJ. Paralisia Facial Periférica no Contexto de Síndrome de Melkersson-Rosenthal - Relato de Caso. 


\section{INTRODUCTION}

Melkersson-Rosenthal syndrome is a noncaseating granulomatous disease characterized by recurrent peripheral facial palsy, recurrent or persistent orofacial edema and a fissured tongue ${ }^{1-6}$. The three typical clinical manifestations of this syndrome can occur either simultaneously or at different times ${ }^{7}$. However, the full clinical triad occurs only in a minority of cases ${ }^{1-3}$. Mono or oligosymptomatic forms are much more common ${ }^{1-4,6,7}$, so this syndrome is frequently under diagnosed ${ }^{8}$.

Its etiology remains unknown, though genetic, allergic and immune factors as well as infectious and traumatic causes have been implicated. It is sometimes described associated to systemic diseases such as Crohn disease ${ }^{5}$.

Although it can affect people of any age or gender, it is more common in women and in the second decade of life ${ }^{5,8}$.

Its diagnosis is mainly clinical, suggested by history and physical examination. However, the definitive diagnosis is obtained with electrophysiological and imaging studies and biopsy of facial swelling areas.

\section{CASE PRESENTATION}

A 39-year-old woman with a past medical history of a recurrent left peripheral facial palsy was referred to Neurology consultation because of blepharospasm in the right eye. Health Ethic Committee of Hospital São João (\#2011-07-07).

Besides blepharospasm in the right eye and residual facial asymmetry resultant from peripheral facial palsy, she complained of involuntary movements of the face and both eyes which were aggravated by stress and anxiety and had a negative psychological impact.

She had the first episode of peripheral facial palsy when she was 11 years-old and did physical therapy. She also had recurrent episodes of orofacial edema since she was 19 years-old. On physical examination, she presented slight left peripheral facial palsy (House-Brackmann scale grade II), blepharospasm in the right eye, spontaneous and brief involuntary muscle contractions in the left eye and left lower face with the appearance of wormlike rippling of the muscle, consistent with myokimias, a slight upper lip edema with local skin changes (figure 1) and a fissured tongue. She had neither compromise of other cranial nerves nor systemic complaints.

She underwent an extensive analytic study, including serologies (EBV, Borrelia, syphilis), viruses markers (HBV, HCV, HIV) and immunological tests, which were within normal limits. Brain MRI and thoracic radiography were normal. She also performed an upper lip biopsy that demonstrated a granulomatous cheilitis. In electrophysiological studies, she demonstrated a pattern compatible with myokimias in electromyographic study of orbicularis oris bilaterally and signs of chronic axonal damage of both facial nerves, consistent with a disease affecting both sides of the face.

She was treated with anti-inflammatory drugs and topical application of hialuronic acid to alleviate the skin lesions and with oral oxcarbamazepine to decrease myokimias of face and eyes. Injections of botulinum neurotoxin type A were administered in the right orbicularis oculi muscle. This treatment resulted in a reduction of her blepharopasm.

\section{DISCUSSION}

Melkersson-Rosenthal syndrome is a hypothesis that should be always considered in the differential diagnosis of recurrent peripheral facial palsy.

In this syndrome, peripheral facial palsy can occur from months to years either before or after the beginning of orofacial swelling. It can be unilateral or bilateral, partial or complete. It appears suddenly and it is clinically indistinguishable of Bell's palsy ${ }^{7,9}$. Facial weakness can be accompanied by taste or hearing disorders, otalgia or

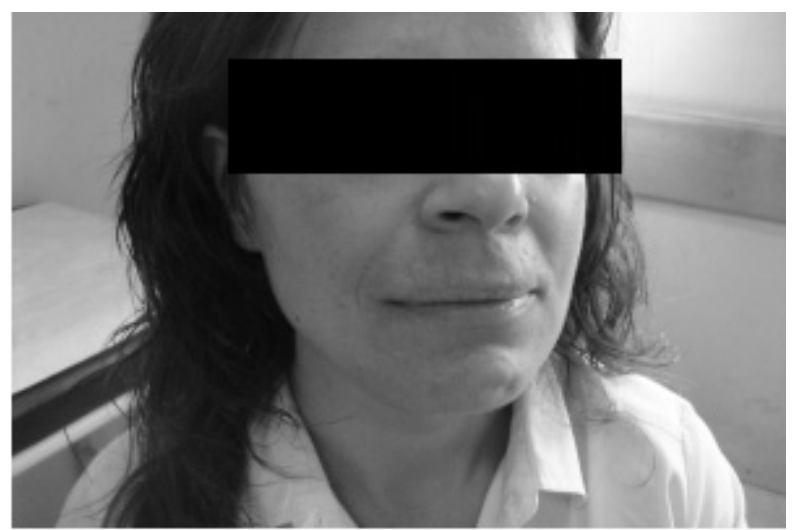

Figure 1. Slight sequelae of left peripheral facial palsy and upper lip edema with local skin changes. 
salivary hyposecretion ${ }^{3}$. Orofacial edema is the dominant feature of Melkersson-Rosenthal syndrome, affecting mainly the upper lip9. It can be either unilateral or bilateral, occurring in the same side of the facial palsy. After several episodes, it can persist indefinitively, causing facial deformities. Fissured tongue (also called lingua plicata or scrotal tongue) is the least frequent clinical feature, is not pathognomic ${ }^{3}$ occurring in general population without meaning disease $\mathrm{e}^{3,10}$. Other findings associated with Melkersson-Rosenthal syndrome include: trigeminal neuralgia, ocular palsies, paresthesias, blepharospasm, lachrymal and salivary gland dysfunction, epiphora, keratitis, psychotic episodes and migraine $e^{7,11}$.

Initially, facial palsy tends to complete recovery within three weeks even without medicines (systemic corticoids like prednisone, which can help reduce facial nerve edema and consequently symptoms) ${ }^{12}$. As disease progresses, facial palsy episodes increase in frequency and duration and may cause residual paresis or sinkinesias. After several relapses, permanent deficits of facial mobility may lead to difficulties in communication or feeding; esthetic changes may appear with potential negative psychological impact ${ }^{13}$. Therefore, it is necessary to rapidly reestablish facial mimic through physical therapy ${ }^{14}$, including neuromuscular proprioceptive facilitation techniques and therapeutic modalities such as orofacial massage, ice massage, facial muscle exercises in front of mirror (biofeedback) and strengthening of facial muscles - essentially the same treatment patterns used in Bell's palsy. Surgery can be an option for patients with recurrent or persistent palsies in whom medical and physical treatments are ineffective, but there is only very low quality evidence ${ }^{15}$.

Worth mentioning in this case report is that besides presenting the typical clinical triad, the patient had focal dystonia in the right eye, blepharospasm and myokimias of the left face due to facial nerve damage progression.

Melkersson-Rosenthal syndrome has to be considered in the differential diagnosis of recurrent peripheral facial palsy. These patients need a regular follow-up, given the chronic and progressive character of the disease.

\section{ACKNOWLEDGMENTS}

Fernando Parada, Teresa Toste (Department of Physical and Rehabilitation Medicine, Hospital de São João, Porto, Portugal).

\section{REFERENCES}

1.Costa AC, Santos AS, Pedro E, Palma-Carlos AG, Pereira-Barbosa M. Síndrome de Melkersson-Rosenthal como causa de edema labial crónico, um desafio diagnóstico. Rev Port Imunoalergol 2004;12:400-13.

2.Alioğlu Z, Çaylan R, Adanir M, Özmenoğlu M. Melkersson-Rosenthal syndrome: report of three cases. Neurol Sci 2000;21:57-60.

http://dx.doi.org/10.1007/s100720070120

3.Cockerham KP, Hidayat AA, Cockerham GC, Depper MH, Sorensen S, Cytryn AS, et al. Melkersson-Rosenthal Syndrome. New Clinicopathologic Findings in 4 Cases. Arch Ophthalmol 2000;118:227-32.

4.Zimmer WM, Rogers RS, Reeve CM, Sheridan PJ. Orofacial manifestations of Melkersson-Rosenthal syndrome: a study of 42 patients and review of 220 cases from the literature. Oral Surg Oral Med Oral Pathol 1992;74:610-9. http://dx.doi.org/10.1016/0030-4220(92)90354-S

5.López JÁ, Santos P, Rodrigues J, Vaz M. Síndrome de Melkersson-Rosenthal. A propósito de um caso clínico. Rev Port Imunoalergol 1999;7:39-41.

6.Izzeddin R, Salas MJ, Acuña A, Salas C, IzzeddinN. Manifestaciones orofaciales del síndrome de Melkersson-Rosenthal. Revisión de la literatura y estudio de un caso. Odous Cientifica 2004;2.

7.Ozgursoy OB, Ozgursoy SK, Tulunay O, Kemal O, Akyol A, Dursun G. Melkersson-Rosenthal syndrome revisited as a misdiagnosed disease. Am J Otolaryngol - Head and Neck Medicine and Surgery 2009;30:33-7.

8.Ang KL, Jones NS. Melkersson-Rosenthal syndrome. J Laryngol Otol 2002;116:386-8.

http://dx.doi.org/10.1258/0022215021910861

9.Greene RM, Rogers RS. Melkersson-Rosenthal syndrome: a review of 36 patients. J Am Acad Dermatol 1989;21:1263-70.

http://dx.doi.org/10.1016/S0190-9622(89)70341-8

10.Chen C, Huilgol SC, James C, Selva D. Melkersson-Rosenthal syndrome presenting with upper lid edema and facial palsy. Can J Ophthalmol 2002;37:361-3.

11.Winnie R, Deluxe DM. Melkersson-Rosenthal syndrome: review of the literature and case report. Int J Oral Maxillofac Surg 1992;21:115-7.

http://dx.doi.org/10.1016/S0901-5027(05)80546-6

12.Salinas RA, Alvarez G, Daly F, Ferreira J. Corticosteroids for Bell's palsy (idiopathic facial paralysis) (Cochrane Review). Cochrane Database of Systematic Reviews. 2010; Issue 9.

13. Vilela DAS, Balieiro FO, Fernandes AMF, Mitre EI, Lazarini PR. Síndrome de Melkersson-Rosenthal: relato de casos e revisão da literatura. Rev Bras Otorrinolaringol 2002;68:755-60.

14. Teixeira LJ, Soares BGO, Vieira VP, Prado GF. Physical therapy for Bell's palsy (idiopathic facial paralysis) (Cochrane Review). Cochrane Database of Systematic Reviews. 2008; Issue 3.

15.Swan I, Donnan P, McAllister K, Walker D. Surgical interventions for the early management of Bell's palsy. Cochrane Database of Systematic Reviews. 2011; Issue 2. 